\title{
Article \\ Construction of a Novel Chimeric Dextransucrase Fused to the Carbohydrate-Binding Module CBM2a
}

\author{
Reinaldo Fraga Vidal ${ }^{1, *(1)}$, Roberto Carlos Arísticas Ribalta ${ }^{1}$, Lisandra Teresa Martínez Valdés ${ }^{1}$, \\ Meinardo Lafargue Gámez ${ }^{1}$, Amanda Montes Alvarez ${ }^{1}$, Arianne Rubio Sánchez ${ }^{1}$, Eric Dubreucq ${ }^{2}$ (D) \\ and Benoît Moreau ${ }^{3}$ \\ 1 Department of Microbiology and Genetics, Cuban Research Institute on Sugarcane By-Products (ICIDCA), \\ P.O. Box 4026, Havana 11000, Cuba; roberto.aristicas@icidca.azcuba.cu (R.C.A.R.); \\ lisandra.martinez@icidca.azcuba.cu (L.T.M.V.); meinardo.lafargue@icidca.azcuba.cu (M.L.G.); \\ amanda.montes@icidca.azcuba.cu (A.M.A.); arianne.rubio@icidca.azcuba.cu (A.R.S.) \\ 2 IATE, Institut Agro, INRAE, Univ. Montpellier, 34060 Montpellier, France; Eric.Dubreucq@supagro.fr \\ 3 Haute Ecole Province de Henaut-Condorcet, Rue Paul Pastur 11, 7800 Ath, Belgium; \\ benoit.moreau@condorcet.be \\ * Correspondence: reynaldo.fraga@icidca.azcuba.cu; Tel.: +53-7-696-7015; Fax: +53-7-988243
}

\section{check for}

updates

Citation: Fraga Vidal, R.; Arísticas Ribalta, R.C.; Martínez Valdés, L.T.; Lafargue Gámez, M.; Montes Alvarez, A.; Rubio Sánchez, A.; Dubreucq, E.; Moreau, B. Construction of a Novel Chimeric Dextransucrase Fused to the Carbohydrate-Binding Module CBM2a. Catalysts 2021, 11, 1179. https://doi.org/10.3390/ catal11101179

Academic Editor: Jose M. Guisan

Received: 30 August 2021

Accepted: 22 September 2021

Published: 28 September 2021

Publisher's Note: MDPI stays neutral with regard to jurisdictional claims in published maps and institutional affiliations.

Copyright: (c) 2021 by the authors. Licensee MDPI, Basel, Switzerland. This article is an open access article distributed under the terms and conditions of the Creative Commons Attribution (CC BY) license (https:/ / creativecommons.org/licenses/by/ $4.0 /)$.

\begin{abstract}
Lactic acid bacteria (LAB) have the potential to produce homoexopolysaccharides (HoPS). Their health benefits and physicochemical properties have been the subject of extensive research. The HoPS functional properties are determined by molecular weight, the type of glycosidic linkages, degrees of branching and chemical composition. The dextransucrases (DSases) produce a kind of HoPS (dextrans), which are among the first biopolymers produced at industrial scale with applications in medicine and biotechnology. The glycodiversification opens additional applications for DSases. Therefore, the design and characterization of new DSases is of prime importance. Previously, we described the isolation and characterization of a novel extracellular dextransucrase (DSR-F) encoding gene. In this study, from DSR-F, we design a novel chimeric dextransucrase DSR-F$\triangle$ SP- $\triangle$ GBD-CBM2a, where DSR-F- $\triangle$ SP- $\triangle$ GBD (APY repeats and a CW repeat deleted) was fused to the carbohydrate-binding module (CBM2a) of the $\beta-1-4$ exoglucanase/xylanase Cex (Xyn10A) of Cellulomonas fimi ATCC 484. This dextransucrase variant is active and the specificity is not altered. The DSR-F- $\triangle$ SP- $\triangle$ GBD-CBM2a was purified by cellulose affinity chromatography for the first time. This research showed that hybrids and chimeric biocatalyst DSases with novel binding capacity to cellulose can be designed to purify and immobilize using renewable lignocellulosic materials as supports.
\end{abstract}

Keywords: dextransucrases; GH70; lactic acid bacteria; sucrose-active enzymes; carbohydratebinding module; glucansucrase; cellulose-binding domain; Leuconostoc

\section{Introduction}

Homoexopolysaccharides (HoPS) produced by lactic acid bacteria (LAB) have been the subject of much research to determine their physicochemical and bioactive properties [1]. The individual functional properties of HoPS are determined by their chemical composition, molecular weights, and types of glycosidic linkages as well as the degree and arrangement of branches [2]. The structural diversity of HoPS is a result of the unmatched variety of possible glycosidic bonds between sugar monomers, offering an extensive range of functionalities of interest for food, feed, pharmaceuticals, cosmetics and chemicals industries [3-6].

Dextrans are among the first microbial HoPS produced at industrial scale [7]. Microorganisms of the genera Lactobacillus, Streptococcus, Weissella and Leuconostoc produce these polysaccharides [8]. The Leuconostoc mesenteroides NRRL B-512F is used for the synthesis of the most common commercial dextran. The biopolymer's main chain contains $\alpha(1-6)$ 
linked glucosyl residues with only $5 \%$ of $\alpha(1-3)$ linked branches [7]. The dextran fractions of controlled molecular weight and their numerous derivatives are mainly used in medicine, pharmaceuticals and fine chemistry $[9,10]$. The extracellular glucansucrase (dextransucrase) DSR-S, a 6- $\alpha$-D-glucosyltransferase (EC 2.4.1.5) is responsible for the polymer production [11]. This enzyme belongs to the glycoside hydrolase family 70 (GH70) according to the CAZy classification (http:/ /www.cazy.org/) (accessed on 20 June 2021) [12]. The GH70 family consists of a large and diverse group of polymerases and branching enzymes, some of them being mainly active on sucrose while others typically use starch substrates $[13,14]$.

The catalytic domain of GH70 presents the typical $(\alpha / \beta)_{8}$ barrel of glucansucrases. The three amino acids (D551, E589, D662, DSR-S numbering) forming the catalytic triad are highly conserved in the GH70 family [15-17].

The study of GH70 enzymes with different specificities from new LAB strains and from mining genome data sets could provide new insights into structure-function relationships of glucansucrases as well as enlarge the natural dextransucrase repertoire available for industrial application [18]. The Cuban Research Institute on Sugarcane By-products (ICIDCA) has a collection of LAB strains isolated from sugarcane and sugarcane derivatives. From those LAB strains, some dextransucrases have already been partially characterized [19-21]. From them, the DSR-F dextransucrase and its truncated variant DSR-F- $\Delta$ SP- $\Delta$ GBD have some common structural and functional characteristics with alternansucrase ASR. However, there are different specificities, as revealed by ${ }^{13} \mathrm{C}$ NMR spectra, which show dextran polymers formed by $\alpha(1-6)(93 \%), \alpha(1-3)(6 \%)$ links, and $\alpha(1-4)(1 \%)$ branches $[19,20]$. In the present study, a chimeric dextransucrase from DSR-F- $\Delta$ SP- $\Delta$ GBD fused to the carbohydratebinding module (CBM2a) of the exoglucanase/xylanase Cex (Xyn10A) of Cellulomonas fimi ATCC 484 was obtained. This variant, fully active, was purified by cellulose affinity chromatography and partially characterized. This chimeric dextransucrase could be purified or fractionated with sugarcane bagasse or bagasse derivatives but also immobilized in those types of renewable supports to produce maltooligosaccharides or modified oligodextrans with potential prebiotic properties.

\section{Results and Discussion}

\subsection{Design of a Chimeric Dextransucrase (DSR-F- $\triangle S P-\triangle G B D-C B M 2 a$ ) Fused to the} Carbohydrate-Binding Module CBM2a

Based on the 3D structural model of DSR-F- $\triangle$ SP- $\triangle$ GBD (Figure 1 III), a chimeric dextransucrase fused to the carbohydrate-binding module CBM2a (DSR-F- $\Delta$ SP- $\triangle$ GBD-CBM2a) was constructed (Figure 1I,III). Deleting the two APY repeat units and a cell wall repeat unit (CW repeat) from the C-terminal end of DSR-F and adding the CBM2a allowed further investigation of this domain fusion on the specificity of the chimeric fused variant.

The recombinant DSR-F- $\Delta$ SP- $\Delta$ GBD enzyme produces a unique mostly linear $\alpha(1-6)$ (93\%) dextran with minor branching $\alpha(1-3)(6 \%)$ and $\alpha(1-4)(1 \%)[19,20]$. This enzyme variant was previously produced without part of its C-terminal glucan-binding domain (Figure 1I, DSR-F- $\Delta$ SP- $\Delta \mathrm{GBD}$ ). The deletion of the C-terminal domain V including the two APY repeats and a cell wall (CW) repeat did not affect the DSR-F- $\triangle$ SP- $\triangle$ GBD specificity and efficiency but increased its solubility during its expression and production in E. coli. [19]. Other examples of APY repeats that have been deleted without adverse effect on other GH70 and related enzymes have been observed in alternansucrase, inulosucrase, and branching sucrase BSR-B [22-24]. 
(I)

(II)

(III)
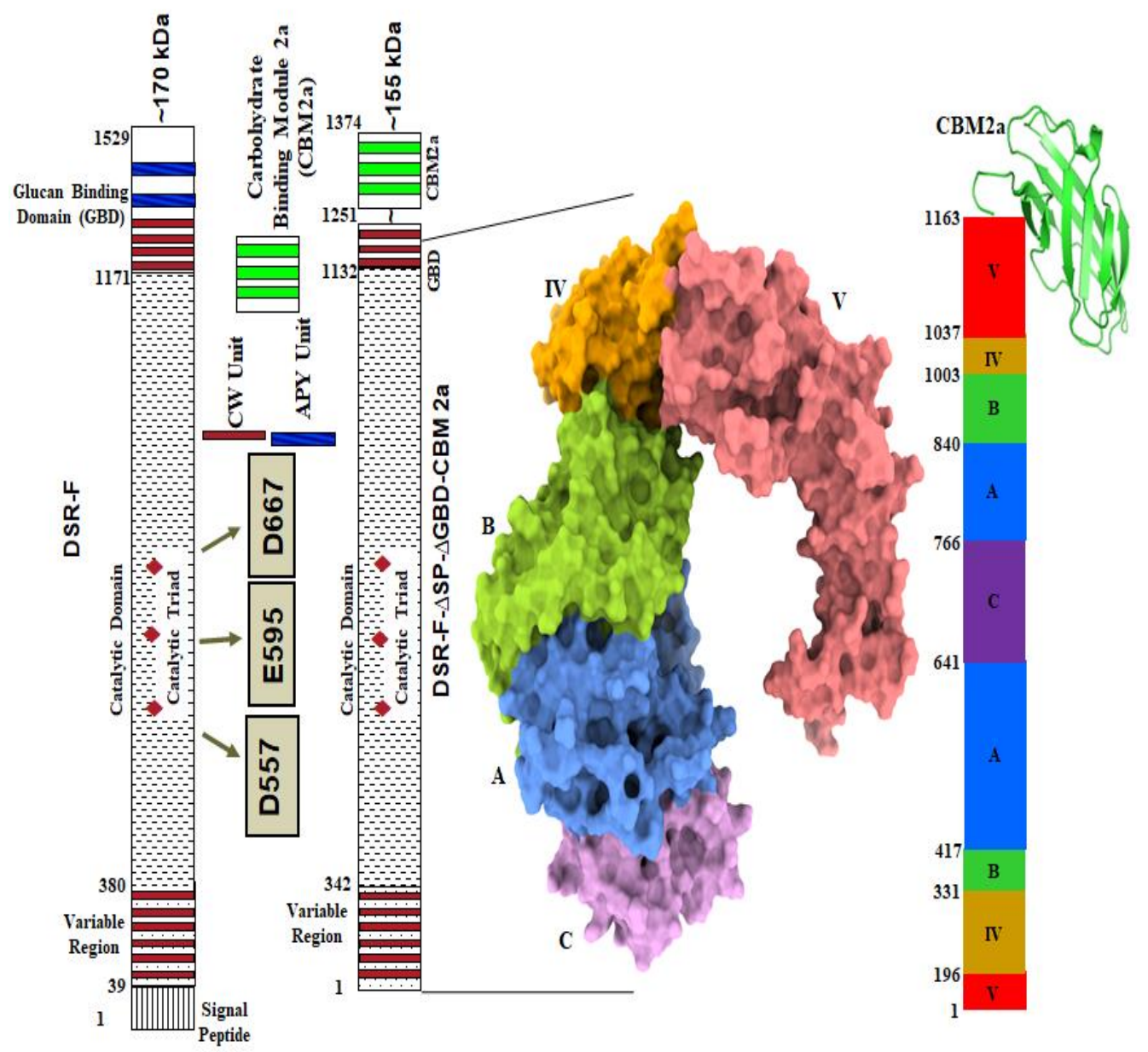

Figure 1. (I). Primary representation of dextransucrase DSR-F of Leuconostoc citreum B/110-1-2 and its deletion mutant variant DSRF- $\Delta$ SP- $\Delta$ GBD. (II). 3D structure model of DSRF- $\Delta$ SP- $\Delta$ GBD, five domains are highlighted, in red (domain V), yellow (domain IV), green (domain B), blue (domain A), and magenta (domain C). (III). Linear schematic representation of DSRF- $\Delta$ SP- $\Delta$ GBD domain organization with CBM2a fused to the C-terminal end.

2.2. Subcloning of DSR-F- $\triangle S P-\triangle G B D$ to Obtain DSR-F- $\triangle S P-\triangle G B D-C B M 2 a$ in the Expression Vector pdsrF-CBM2a and Purification of the Fusion Protein DSR-F- $S P P-\triangle G B D-C B M 2 a$

The construction of plasmid pdsrF-CBM2a allows the inducible expression of DsrF$\triangle \mathrm{SP}-\triangle \mathrm{GBD}$ fused in its carboxyl end region with the carbohydrate-binding module CBM2a of Cex, a $\beta$-1,4-exo-glucanase of Cellulomonas fimi ATCC 484. The fusion of the CBM2a to a dextransucrase is reported for the first time. The presence of the CBM2a module seems to not affect the ability to form dextran polymer by the fusion enzyme DsrF- $\Delta S P-\Delta G B D-$ CBM2a (Figure 2I,II), and it will permit its purification for further characterization and future immobilization on cellulosic or lignocellulosic materials. A successful dextransucrase fusion for immobilization is the case of DSR-S from Leuconostoc mesenteroides B-512FMC to glutathione S-transferase (GST), resulting in a novel and completely active fused truncated variant [25]. 

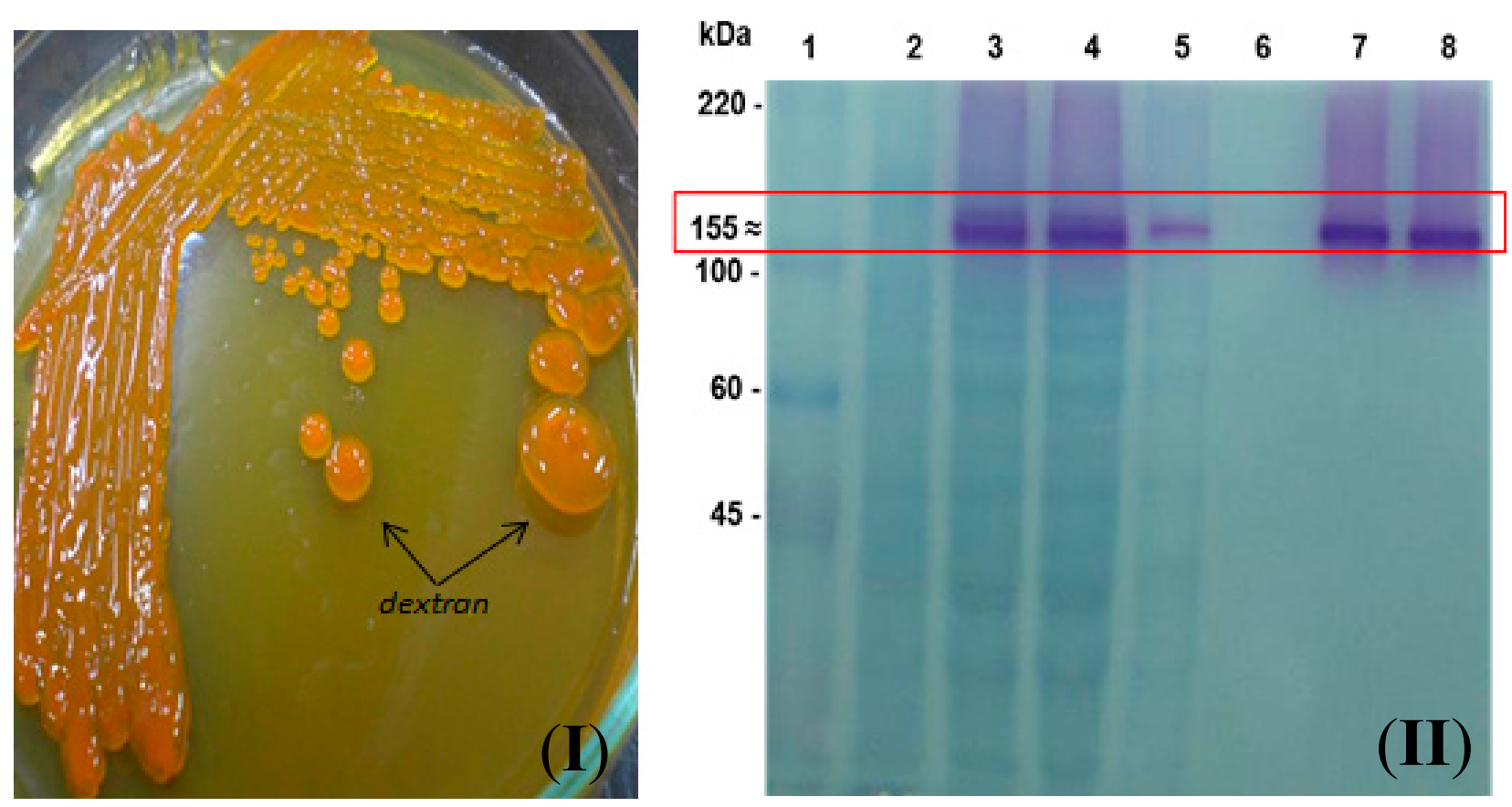

Figure 2. Production of DsrF- $\Delta$ SP- $\triangle$ GBD-CBM2a in E. coli DH10B. (I) Detection of dextransucrase activity through the formation of dextran on LBT agar plate. (II) SDS-PAGE of DsrF- $\Delta$ SP- $\Delta$ GBD-CBM2a purification, stained combining two detection methods. Zymography of the proteins with dextransucrase activity (colored bands), followed by detection of total proteins by negative staining with imidazole and zinc sulfate salts (transparent bands). The formation of the dextran polymer demonstrates the activity of the fusion. (1) Molecular Weight Marker (ColorBurst ${ }^{\mathrm{TM}}$, Sigma-Aldrich Co.). (2) Soluble fraction of E. coli DH10B (pSE380) cell lysate as negative control. (3) Soluble fraction of E. coli DH10B (pdsrF-CBD) cell lysate. (4) Flowthrough fraction, not retained by the RAC. (5) Fraction of the 1st wash of the column (8 Column Volumes, CV). (6) Fraction of the 2nd wash of the column (12 CV). (7 and 8) Fractions eluted.

The purification of DsrF- $\Delta$ SP- $\Delta$ GBD-CBM2a from the soluble fraction of the E. coli DH10B (pdsrF-CBM2a) was performed using regenerated amorphous cellulose (RAC) as an affinity resin. The purified protein migrated as a single band with an apparent molecular mass of $155 \mathrm{kDa}$ and a $90-95 \%$ purity estimated by densitometry (Figure 2II). This is the first report of the use of a cellulose-based matrix for the purification of a dextransucrase by affinity chromatography. The levels of purified protein are greater than those achieved by the immobilized metal ion affinity chromatography (IMAC) (data not shown). This may be because RAC has a higher binding capacity (365 $\mathrm{mg}$ of protein per gram of RAC) than any other commercial resin used to purify proteins (10-40 $\mathrm{mg}$ of proteins per gram of resin) [26]. However, the purification conditions tested were not optimized, explaining why a lot of enzyme was not retained by the cellulose resin. Changing some purification parameters such as the ratio of crude extract protein to resin would improve the procedure.

\subsection{Action of DSR-F- $\triangle S P-\triangle G B D-C B M 2 a$ in Polymerization and Acceptor Reactions}

A polymerization reaction with sucrose was carried out to ensure the chimeric DSRF- $\Delta$ SP- $\Delta$ GBD-CBM2a behaves in the same way as the DSR-F- $\Delta$ SP- $\Delta$ GBD variant. Dextransucrase GTF180 from $L b$. reuteri 180 [27] and alternansucrase (ASR) from L. citreum NRRL B-1355 [28], DSR-F- $\Delta$ SP- $\Delta$ GBD-CBM2a and DSR-F- $\Delta$ SP- $\Delta$ GBD are also striking examples of $\alpha$-transglucosylases among GH70 glucansucrases. They catalyze a bi-modal population of glucan, comprising a high-molar mass (HMM, $\left.2 \times 10^{6} \mathrm{~g} \cdot \mathrm{mol}^{-1}\right)$ dextran and low-molar mass gluco-oligosaccharides (LMM, DP $<8$, around $1300 \mathrm{~g} \cdot \mathrm{mol}^{-1}$ ) from sucrose, as estimated by size exclusion chromatography (Figure 3I). 

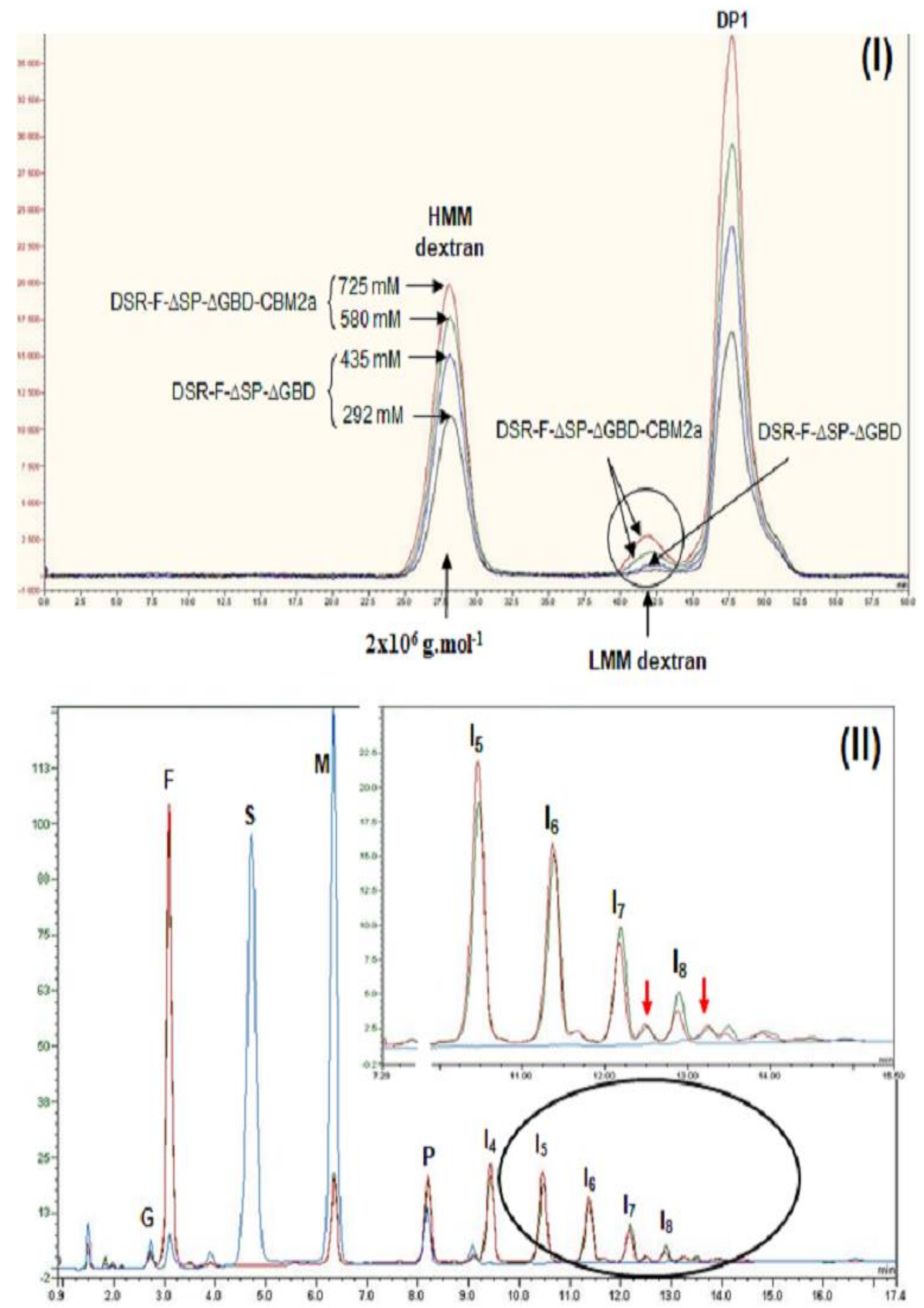

Figure 3. (I) Analysis of HPSEC chromatograms synthesized using the chimeric dextransucrase DSRF- $\triangle$ SP- $\triangle$ GBD-CBM2a (from 580 and $725 \mathrm{mM}$ sucrose) and DSR-F- $\triangle$ SP- $\Delta$ GBD (from 292 and $435 \mathrm{mM}$ sucrose) with $50 \mathrm{mM}$ sodium acetate buffer, $\mathrm{pH} 5.5$ and $1 \mathrm{U} \cdot \mathrm{mL}^{-1}$ enzyme. Enzymatic reactions were stopped after $24 \mathrm{~h}$. Peak identification: HMM dextran-high-molecular mass dextran $\left(2 \times 10^{6} \mathrm{~g} \cdot \mathrm{mol}^{-1}\right.$ as estimated by HPSEC), LMM dextran-low-molecular mass dextran (oligosaccharides of DP <8), DP1-fructose. (II) Analysis of HPAEC-PAD chromatogram products synthesized using DSR-F- $\triangle$ SP$\triangle$ GBD-CBM2a (green line) and DSR-F- $\triangle$ SP- $\triangle$ GBD (red line) from sucrose (292 mM) and maltose $(146 \mathrm{mM})$ with $20 \mathrm{mM}$ sodium acetate buffer, $\mathrm{pH} 5.5$ and $1 \mathrm{U} \cdot \mathrm{mL}^{-1}$ enzyme. Enzymatic reactions were stopped after $24 \mathrm{~h}$. Arrows indicate extra peaks after products with degrees of polymerization (DP) of 7 and 8. Peak identification: G-glucose, F-fructose, S-sucrose, $\mathrm{M}$-maltose, $\mathrm{P}$-panose (DP3), I4-I8-isomaltooligosaccharides of DP4-DP8. The line with the highest signal of S and M and no detection of isomaltooligosaccharides corresponds to the initial reaction time ( $\mathrm{t}=0 \mathrm{~min}$, blue line). 
This result corroborates the dextran formation observed in Figure 2I,II. In addition, it suggests a semi-processive elongation mechanism, as for other GH70 enzymes, where smaller oligosaccharides are produced in a non-processive mode at the beginning of the reaction. When a critical length is reached, a processive mechanism, mediated by polymerbinding regions in the enzyme, starts, helped by the glucan-binding domain to facilitate HMM dextran formation [29,30]. The horseshoe shaped putative structure of DSR-F- $\Delta$ SP$\triangle$ GBD-CBM2a and DSR-F- $\Delta$ SP- $\Delta$ GBD (Figure 1II) could give high flexibility to domain $V$ like in others GH70, which in combination with several putative binding pockets identified (Figure 4I,II) could promote a local increase in dextran concentration around the catalytic site for chain elongation.
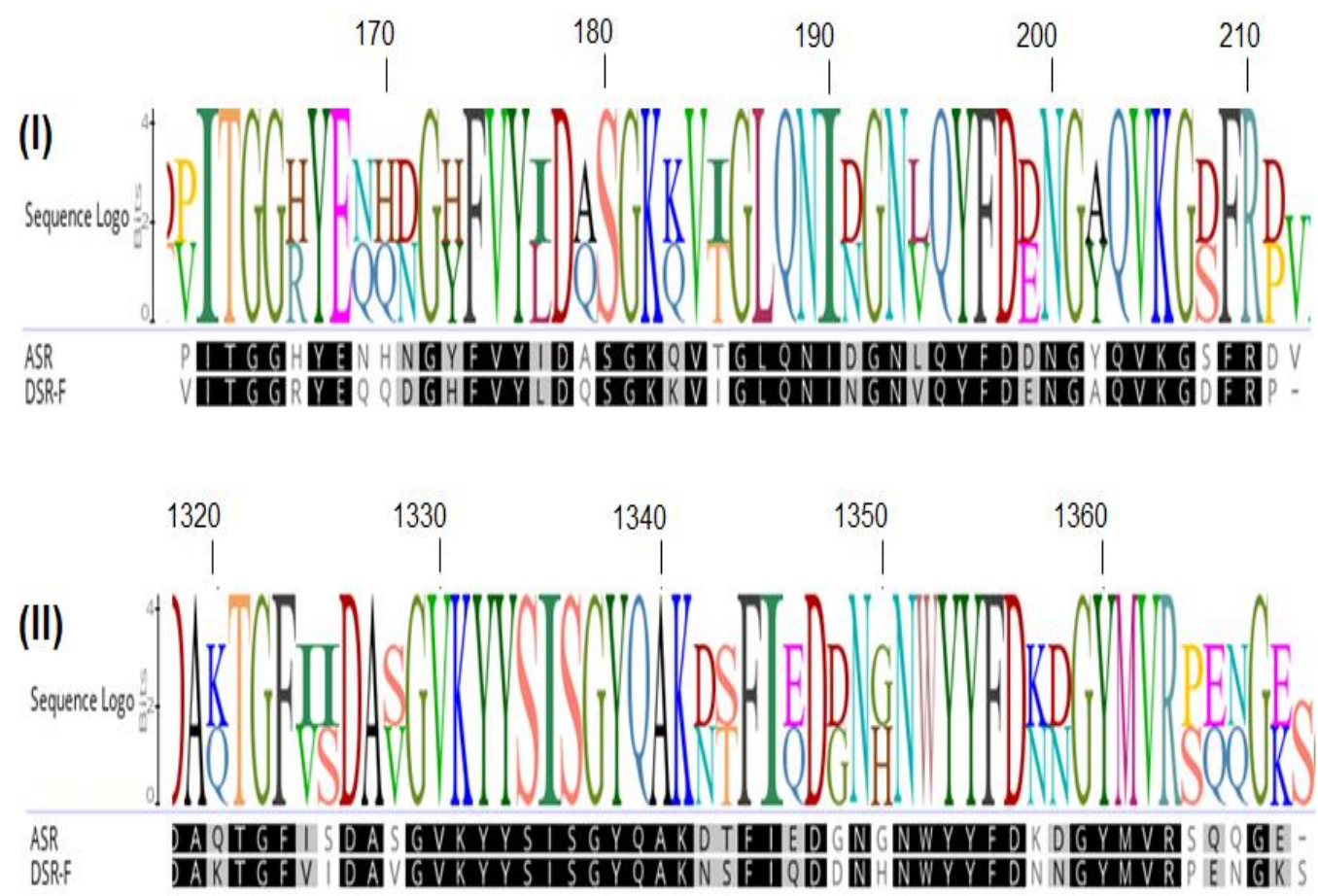

Figure 4. Domain V sugar-binding pockets sequence comparison. Alignment of the residues corresponding to two sugar-binding pockets V-A (I) and V-C (II) of alternansucrase ASR from L. citreum NRRL B-1355 (PDB entry 6SYQ) with the equivalent residues in dextransucrase DSR-F.

In the acceptor reaction (maltose as the acceptor molecule) performed with DSR-F- $\Delta S P$ $\triangle \mathrm{GBD}-\mathrm{CBM} 2 \mathrm{a}$, a series of analog isomaltodextrins very similar to the ones produced by the recombinant dextransucrase DSR-F- $\Delta$ SP- $\Delta$ GBD from L. citreum B/110-1-2 (Figure 3II) were synthesized. The isomalto-oligosaccharide (IMO) products with 7 and 8 glucose units showed two extra peaks (Figure 3II, arrows), indicating that they were decorated with at least one branched $\alpha(1-4)$ glucose unit. These IMO products correspond to previously characterized oligodextrans [20]. From these observations, it seems that the cellulose-binding domain of DSR-F- $\Delta$ SP- $\triangle$ GBD-CBM2a does not affect the synthesis of HMM and LMM glucans from sucrose and IMO products from sucrose/maltose, respectively. 


\subsection{Action of DSR-F- $\triangle S P-\triangle G B D-C B M 2 a$ from Sucrose and Linear Oligodextrans (1500 and $6000 \mathrm{~g} \cdot \mathrm{mol}^{-1}$ )}

A reaction with sucrose $(292 \mathrm{mM}), 1500 \mathrm{~g} \cdot \mathrm{mol}^{-1}$ dextran $(66.6 \mathrm{mM})$, a linear $\alpha(1-6)$ glucan with a mean DP of 9 was performed. Analyses of the reaction products showed that a low amount of leucrose was detected due to the action of fructose as an acceptor (Figure 5IB,C). This kind of transglycosylation has been reported to be favored at the start of the dextransucrase reactions $[29,31]$. It has been recently suggested that leucrose acts as the substrate for further dextran formation or elongation of IMOs [32]. The IMOs from DP8 to DP12 were glucosyl decorated in the same way by the chimeric dextransucrase DSR-F$\Delta$ SP- $\Delta$ GBD-CBM2a and DSR-F- $\Delta$ SP- $\Delta$ GBD, leading to the formation of products clearly observable on HPAEC-PAD chromatograms (Figure $5 \mathrm{IB}, \mathrm{C}$, arrows). Such chromatographic patterns resulting from the acceptor reaction (oligodextrans as the acceptor molecules) is reported for the first time for a DSR-F variant enzyme. According to the specificity of both analyzed enzymes, these modified IMOs could be products partially glucosylated and likely altered by addition of $\alpha(1-4)$ branched glucose units. As a specific population of IMOs seems to act as acceptor molecules to be branched, two factors could be involved with this observation. Structural analyses of dextrans have identified a relation between the degree of branching and the rms charge radii of the polymers wherein a higher proportion of more branched and more compact dextrans is formed. On the other hand, branching may also depend on the steric properties of the glucosyl-donor in the active site of the enzyme [32]. However, the structure of these products (DP8-DP12) must be elucidated in more detail.

A reaction using sucrose $(292 \mathrm{mM})$ and $6000 \mathrm{~g} \cdot \mathrm{mol}^{-1}$ dextran $(66.6 \mathrm{mM})$, a linear $\alpha(1-6)$ glucan or oligodextran with a mean degree of polymerization of 37 was performed. As seen on the HPAEC-PAD chromatograms, the product profile after a $24 \mathrm{~h}$ reaction was different from the initial reaction profile. As in the previous reaction, a low amount of leucrose was detected. Analyses of the final reaction products showed the intensity of several peaks corresponding to isomaltooligosaccharides decreased, suggesting those products were modified in a similar way by DSR-F- $\Delta$ SP- $\Delta$ GBD-CBM2a and DSR-F- $\Delta$ SP- $\Delta$ GBD enzymes (Figure 5IIB,C, arrows). The depletion of all low-molecular weight oligosaccharides suggests such molecules are acting as glucosyl acceptors and are further elongated, probably because in both enzymes some kind of interaction with IMOs are taking place. Recently, the first functional surface binding site (SBS-A1) for a GH70 family enzyme (ASR) was described. It binds isomaltose, isomaltotriose, isomaltononaose, panose and oligoalternan [30]. An alignment sequence of SBS-A1 and the equivalent residues in dextransucrase DSR-F is shown in Figure 6. Several residues are highly conserved in both sequences which could be associated with a similar functionality in DSR-F. From the product analysis of the reactions performed in this study, it seems that dextransucrase DSR-F variants show a strong transferase activity since sucrose was completely consumed and the contents of free glucose and leucrose seem to be much lower than fructose. Therefore, further studies are needed to corroborate a potential utilization of short IMOs as glucosyl acceptors during dextran synthesis and dextran modifications by dextransucrase- $\alpha$-transglucosylases enzymes. 

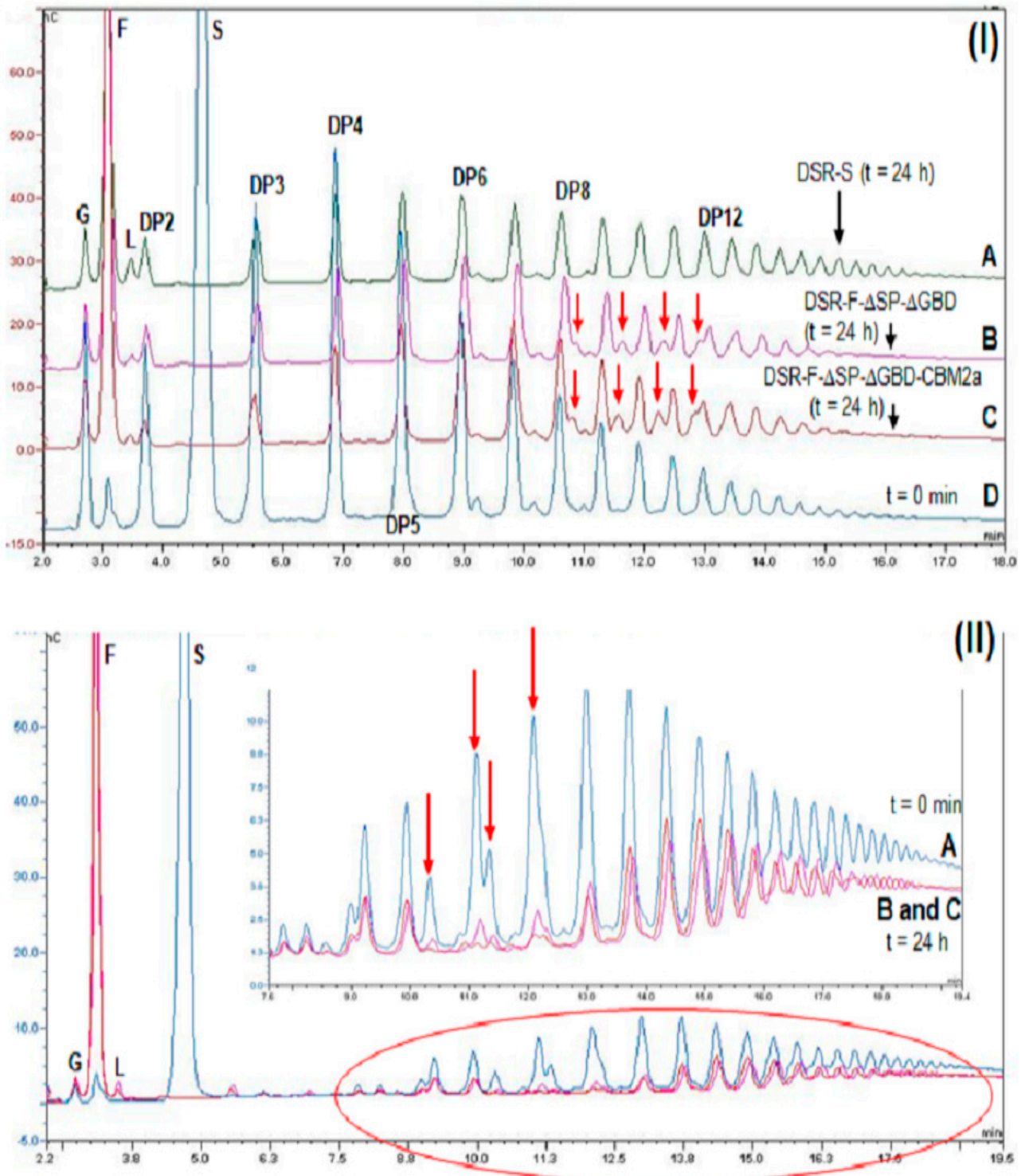

Figure 5. (I) Analysis of HPAEC-PAD chromatogram products synthesized using the chimeric dextransucrase DSR-F- $\Delta$ SP- $\Delta$ GBD-CBM2a, DSR-F- $\triangle$ SP- $\triangle$ GBD and native dextransucrase DSR-S from Leuconostoc mesenteroides NRRL B-512F from sucrose $(292 \mathrm{mM})$ and dextran $1500 \mathrm{~g} \cdot \mathrm{mol}^{-1}(66.6 \mathrm{mM})$ with $20 \mathrm{mM}$ sodium acetate buffer, $\mathrm{pH} 5.5$ and $1 \mathrm{U} \cdot \mathrm{mL}^{-1}$ enzyme. Enzymatic reactions were stopped after $24 \mathrm{~h}, \mathrm{nC}$, (nanocoulombs). I-(A) Enzymatic reaction using DSR-S from L. mesenteroides NRRL-B512; I-(B) enzymatic reaction using DSR-F- $\triangle$ SP- $\triangle$ GBD recombinant; I-(C) enzymatic reaction using chimeric dextransucrase DSR-F- $\triangle$ SP- $\triangle$ GBD-CBM2a; I-(D) enzymatic reaction using chimeric dextransucrase DSR-F- $\Delta$ SP- $\triangle$ GBD-CBM2a at the initial time $(\mathrm{t}=0 \mathrm{~min})$. Arrows indicate four extra peaks immediately after the products with degrees of polymerization (DP) of 8-12, respectively. (II) Analysis of HPAEC-PAD chromatogram products synthesized using the chimeric dextransucrase DSR-F- $\Delta$ SP- $\triangle$ GBD-CBM2a and DSR-F- $\Delta$ SP- $\Delta$ GBD sucrose $(292 \mathrm{mM})$ and $6000 \mathrm{~g} \cdot \mathrm{mol}^{-1}$ dextran $(66.6 \mathrm{mM})$ with $20 \mathrm{mM}$ sodium acetate buffer, $\mathrm{pH} 5.5$ and $1 \mathrm{U} \cdot \mathrm{mL}^{-1}$ enzyme. Enzymatic reactions were stopped after $24 \mathrm{~h}$. II-(A) Enzymatic reaction using chimeric dextransucrase DSR-F- $\Delta$ SP- $\Delta$ GBDCBM2a at the initial time ( $\mathrm{t}=0 \mathrm{~min})$; II-(B) and II-(C) enzymatic reaction using DSR-F- $\Delta$ SP- $\Delta$ GBDCBM2a and DSR-F- $\triangle$ SP- $\triangle \mathrm{GBD}$, respectively. Arrows indicate peaks corresponding to modified dextrans from the initial reaction time. Peak identification: G-glucose, F-fructose, L-leucrose, S-sucrose, DP2-DP12-isomaltooligosaccharides with a degree of polymerization (DP) from 2 to 12. 


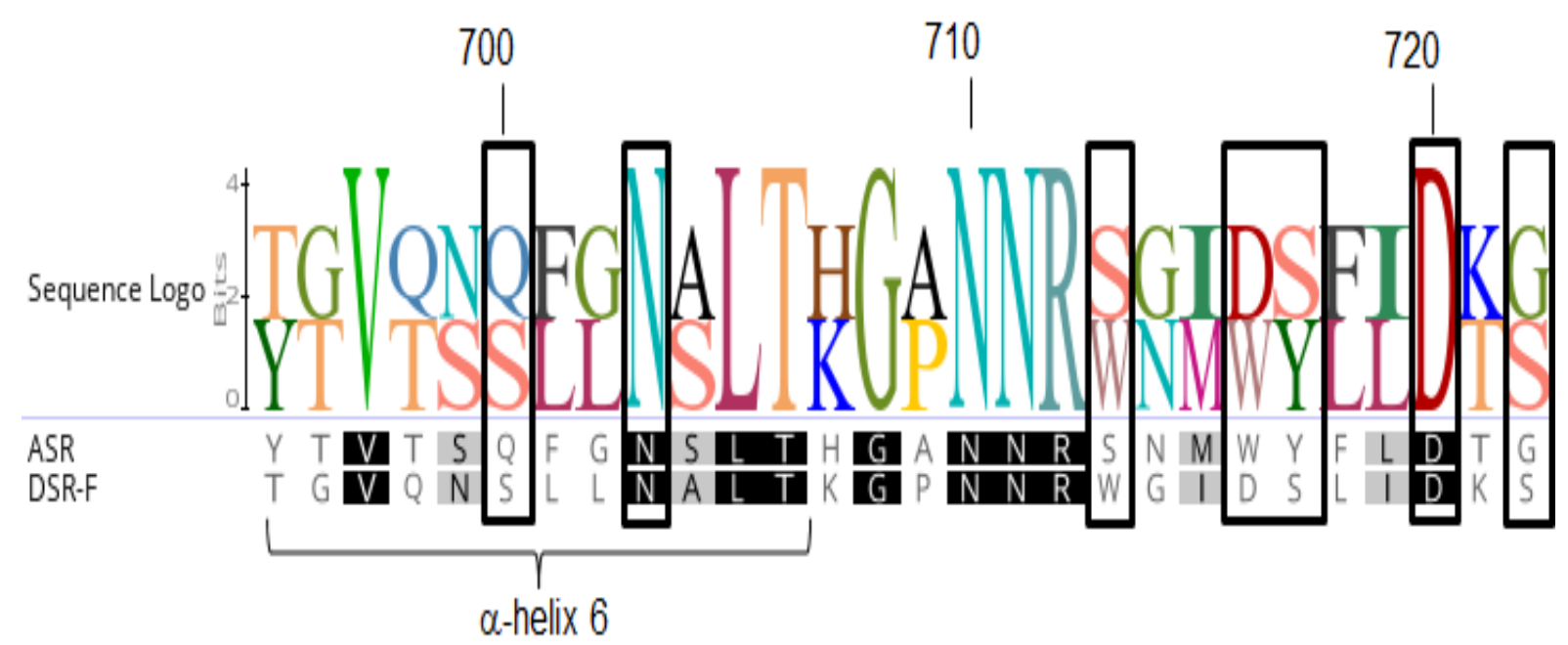

Figure 6. Surface binding site (SBS-A1) sequence comparison. Alignment of the residues corresponding to SBS-A1 of alternansucrase ASR (in black boxes) from L. citreum NRRL B-1355 (numbered and $\alpha$-helix 6 according to ASR in complex with isomaltotriose, PDB entry 6SYQ) with the equivalent residues in dextransucrase DSR-F.

\section{Materials and Methods}

\subsection{Bacterial Strains and Culture Media}

Escherichia coli DH10B was used for the subcloning steps and for protein expression with the pSE380 vector (Invitrogen, Waltham, MA, USA). The screening of E. coli colonies producing functional dextransucrase enzymes was carried out using LBT agar medium [11,20]. Briefly, LBT agar was supplemented with the $\mathrm{pH}$ indicator bromothymol blue $(0.025 \%)$ (Sigma, Saint Louis, MO, USA), 5\% sucrose (Sigma, USA) and 1\% glycerol as extra carbon sources, IPTG (0.08\%) (Sigma, USA), ampicillin (100 $\left.\mu \mathrm{g} \mathrm{mL}^{-1}\right)$ (Sigma, USA). E. coli was grown and maintained on LB medium supplemented when needed with ampicillin $\left(100 \mu \mathrm{g} \mathrm{mL}{ }^{-1}\right)$. All strains were stored at $-80{ }^{\circ} \mathrm{C}$ in $15 \%$ glycerol.

\subsection{Subcloning to Express the dsrF- $\triangle S P-\triangle G B D-C B M 2 a$ Gene in E. coli}

All plasmids for the subcloning steps are listed in Table 1. The $3.7 \mathrm{~kb}$ fragment encoding the truncated variant of DsrF (DsrF- $\Delta$ SP- $\Delta$ GBD) was digested with the restriction enzymes NcoI-EcoRI from the pSEdsrF plasmid and inserted into the plasmid pET38b (+) (Novagen, Madison, WI, USA), which was also digested with the same restriction enzymes, to create the $9.5 \mathrm{~kb}$ pETdsrF plasmid $\left(\mathrm{Km}^{\mathrm{r}}\right)$ after the ligation of both fragments. The latter contains the truncated variant dsrF- $\Delta$ SP- $\triangle$ GBD under the inducible promoter PT7lac, fused at the $3^{\prime}$ end to the signal peptide of the exo- $\beta-1,4$-glucanase Cex from Cellulomonas fimi ATCC 484, at the $5^{\prime}$ end of the cellulose-binding module (CBM2a) of said enzyme, and to the $\mathrm{His}_{8}$ tag. Likewise, the truncated variant is also fused to the $5^{\prime}$-terminus of the transcription terminator of bacteriophage T7. The strain of E. coli DH10B was transformed with the plasmid pETdsrF, which was subsequently purified and digested with the restriction enzymes NcoI-AvrII releasing the $d s r \mathrm{~F}-\Delta \mathrm{SP}-\Delta \mathrm{GBD}$ fused with the CBM2a and the His 8 tag. This fragment was ligated to the equally digested pSE380 plasmid NcoI-AvrII, giving rise to the $8.4 \mathrm{~kb}$ pdsrF-CBM2a plasmid $\left(\mathrm{Ap}^{\mathrm{r}}\right)$ containing the $d s r \mathrm{~F}-\Delta \mathrm{SP}-\Delta \mathrm{GBD}-\mathrm{CBM} 2 \mathrm{a}$ fragment under the inducible Ptrc promoter, fused at the end $3^{\prime}$ to the terminator of the transcription of E. coli rrnBt1-t2. The strain of E. coli DH10B was transformed with this plasmid. 
Table 1. Plasmids used in this work.

\begin{tabular}{|c|c|c|}
\hline Plasmids & Description & Reference \\
\hline pET38b(+) & $\begin{array}{l}\text { Replicon colE1, vector used for protein production in E. coli, fused to the } \\
\text { signal secretion Cex downstream the PT7lac promoter. It harbours the } \\
\text { encoding region for the Carbohydrate-Binding Module. (CBM2a) and a } \\
\qquad \text { His }_{8} \text { tag, } \mathrm{Km}^{\mathrm{r}} \text {, size: } 5.8 \mathrm{~kb} \text {. }\end{array}$ & Novagen \\
\hline pSE380 & $\begin{array}{l}\text { Replicon colE1, vector used for protein production in E. coli downstream } \\
\text { the PTrc promoter, Ap }{ }^{\mathrm{r}} \text {, size: } 4.4 \mathrm{~kb} \text {. }\end{array}$ & Invitrogen \\
\hline pSEdsrF & $\begin{array}{l}\text { pSE380 NcoI-EcoRI, fused to the } 3.7 \mathrm{~kb} \text { amplicon NcoI-EcoRI obtained } \\
\text { from pGEMdsrF. Harbours the truncated variant DsrF- } \Delta S P-\Delta G B D, A^{r} \\
\text { size: } 8.1 \mathrm{~kb}\end{array}$ & [19] \\
\hline pETdsrF & $\begin{array}{l}\mathrm{pET38b}(+) \text { NcoI-EcoRI, fused to the } 3.7 \mathrm{~kb} \text { (DsrF- } \Delta \text { SP- } \Delta \mathrm{GBD}) \text { NcoI-EcoRI } \\
\text { from pSEdsrF, } \mathrm{Km}^{\mathrm{r}} \text {, size: } 9.5 \mathrm{~kb} .\end{array}$ & This work \\
\hline pdsrF-CBM2a & $\begin{array}{c}\text { pSE380 NcoI-AvrII, fused to the } 4.2 \mathrm{~kb} \text { DNA fragment } \\
\text { (DsrF- } \Delta \text { SP- } \Delta \text { GBD-CBM2a) NcoI-AvrII from pETdsrF, Ap }{ }^{\mathrm{r}} \text {, size: } 8.6 \mathrm{~kb} \text {. }\end{array}$ & This work \\
\hline
\end{tabular}

\subsection{Inducible Production of DSR-F- $\triangle S P-\triangle G B D-C B M 2 a$ in E. coli}

For the production of the recombinant dextransucrase DsrF- $\Delta$ SP- $\triangle$ GBD-CBM2a, a colony of the recombinant strain of E. coli DH10B (pdsrF-CBM2a) was inoculated in $100 \mathrm{~mL}$ invaginated flasks with $10 \mathrm{~mL}$ of $2 x Y T$ medium supplemented with $100 \mathrm{mM}$ Tris $/ \mathrm{HCl}, \mathrm{pH} 6.4,100 \mu \mathrm{g} \cdot \mathrm{mL}^{-1}$ ampicillin at $30^{\circ} \mathrm{C}$, and grown overnight at $175 \mathrm{r} \cdot \mathrm{min}^{-1}$. The next day, the cultures were diluted 1:100 with the same medium, supplemented with ampicillin $200 \mu \mathrm{g} \cdot \mathrm{mL}^{-1}$ and grown at $30^{\circ} \mathrm{C}$ to an $\mathrm{OD}(600 \mathrm{~nm}) 0.5$ with shaking at $175 \mathrm{r} \cdot \mathrm{min}^{-1}$. Isopropyl-1-thio- $\beta$-D-galactopyranoside (IPTG) (inducer of the Ptrc promoter) was added at a final concentration of $2.4 \mathrm{mmol} \cdot \mathrm{L}^{-1}$ and incubated for $12-14 \mathrm{~h}$ at $20{ }^{\circ} \mathrm{C}$ with shaking at $175 \mathrm{r} \cdot \mathrm{min}^{-1}$. The cells were collected by centrifugation (Eppendorf $5804 \mathrm{R}$ centrifuge) at $10,000 \times \mathrm{g}$ for $15 \mathrm{~min}$ at $4{ }^{\circ} \mathrm{C}$ and resuspended in the rupture buffer $(50 \mathrm{mM}$ NaAc, pH 5.4, Triton $\mathrm{X} 1000.1 \%(v / v), \mathrm{CaCl}_{2} 0.05 \mathrm{~g} \cdot \mathrm{L}^{-1}$, cocktail of protease inhibitors (Roche)) up to an OD $(600 \mathrm{~nm})$ of 80 . Cell disruption was performed by ultrasound in a disruptor (MSP, Berks, England). The sample (always kept on ice) was exposed to seven cycles of $1 \mathrm{~min}$, at a constant amplitude of 28 microns, with one minute of rest between cycles. The lysate extract was centrifuged (Eppendorf $5804 \mathrm{R}$ centrifuge) at $21,390 \times g$ for $40 \mathrm{~min}$, and the soluble and insoluble fraction of each cell extract was recovered. The samples were stored at $-20^{\circ} \mathrm{C}$ until they were used in other analyses.

\subsection{Cellulose Affinity Chromatography (CAC)}

The chimeric DSR-F- $\triangle$ SP- $\triangle$ GBD-CBM2a was purified by cellulose affinity chromatography (CAC). For this, a matrix of regenerated amorphous cellulose (RAC) obtained from Microgranular Cellulose CC31 (Whatman, Florham Park, NJ, USA) was used [33]. The soluble fraction of the sonicate extract $(10 \mathrm{~mL})$ was mixed by slow agitation with $5 \mathrm{~mL}$ of RAC for $2 \mathrm{~h}$ at $4{ }^{\circ} \mathrm{C}$. The enzyme bound to the matrix was recovered by centrifugation (Eppendorf $5804 \mathrm{R}$, Hamburg, Germany) at $3500 \times g$ for $5 \mathrm{~min}$ and packed in a $10 \mathrm{~mL}$ column $(10 \mathrm{~cm} \times 2 \mathrm{~cm} \varnothing)$. The protein was eluted with $10 \mathrm{~mL}$ of glycerol $99 \%$.

\subsection{Determination of Enzymatic Activity Dextransucrase}

The enzymatic activity assay was performed at 30 and $40{ }^{\circ} \mathrm{C}$, in $20 \mathrm{nM}$ sodium acetate buffer (pH 5.4), $0.05 \mathrm{~g} \cdot \mathrm{L}^{-1} \mathrm{CaCl}_{2}, 1 \mathrm{~g} \cdot \mathrm{L}^{-1} \mathrm{NaN}_{3}$, and $100 \mathrm{~g} \cdot \mathrm{L}^{-1}$ sucrose. The saccharolytic activity was determined by detecting the levels of free reducing sugars with the dinitrosalicylic acid (DNSA) method [34]. One unit of activity was defined as the amount of enzyme that catalyzed the release of $1 \mu \mathrm{mol} \cdot \mathrm{min}^{-1}$ of fructose under the conditions tested. The concentration of proteins was determined according to [35] using BSA as a standard. All determinations were made in triplicate. 


\subsection{SDS-PAGE and Zymograms}

Protein electrophoresis under denaturing conditions (SDS-PAGE) was performed with the XCell SureLock ${ }^{\mathrm{TM}}$ Mini-Cell system, with NOVEX Tris-Acetate gels of $1.5 \mathrm{~mm}$ thickness, NuPAGE $^{\circledR}$ antioxidant and NuPAGE ${ }^{\circledR}$ Tris-Acetate SDS Running Buffer (for Tris-Acetate gels) from Invitrogen. The NuPAGE ${ }^{\circledR}$ Sample Reducing Agent $(3 \mathrm{~mL})$ and NuPAGE ${ }^{\circledR}$ LDS Sample Buffer (X4) $(7.5 \mathrm{~mL})$ were mixed with $20 \mu \mathrm{L}$ of sample and heated at $70^{\circ} \mathrm{C}$ for $10 \mathrm{~min}$ prior to being loaded onto gels. Samples containing suspended cells were centrifuged at $10,000 \times g$ in a micro-centrifuge before being applied to the gels. Approximately $2 \mathrm{mU}$ of enzyme was loaded onto the gels and electrophoresis was carried out for $1 \mathrm{~h}$ at $150 \mathrm{~V}$. The gels were stained for dextransucrase activity in situ (based on Schiff's reaction) according to the procedure of [36] in combination with a reversible negative protein staining method [37]. Briefly, after Schiff's staining, the gel was soaked in a solution $(\sim 50 \mathrm{~mL})$ of Imidazole-SDS (20 $\mathrm{mM}$ and $0.1 \%$, respectively) for $30 \mathrm{~min}$. This solution was discarded, $\sim 30 \mathrm{~mL}$ of $\mathrm{ZnSO}_{4}$ $20 \mathrm{mM}$ was added, and shaken by hand on a dark surface until the protein bands became visible. To stop this reaction, the solution was discarded and the gel was washed several times with deionized water. Precision Plus Protein ${ }^{\mathrm{TM}}$ All Blue Standard was included in all electrophoresis runs.

\subsection{Production of High-Molecular Weight Dextrans, Maltooligosaccharides, and Linear Dextran Modification}

High-molecular-weight dextran synthesis was performed at $40{ }^{\circ} \mathrm{C}$ for $24 \mathrm{~h}$, in buffer $20 \mathrm{mM} \mathrm{NaAc}\left(\mathrm{pH}\right.$ 5.4), $0.05 \mathrm{~g} \cdot \mathrm{L}^{-1} \mathrm{CaCl}_{2}, 1 \mathrm{~g} \cdot \mathrm{L}^{-1} \mathrm{NaN}_{3}, 100 \mathrm{~g} \cdot \mathrm{L}^{-1}$ sucrose and $1 \mathrm{U} \cdot \mathrm{mL}^{-1}$ enzyme. Maltooligosaccharides were produced under the same conditions, except maltose $50 \mathrm{~g} \cdot \mathrm{L}^{-1}$ was added to the reaction. Linear dextrans were modified under the same conditions but $66.6 \mathrm{mM}$ of $\alpha-1,6$ dextrans $\left(1500 \mathrm{~g} \cdot \mathrm{mol}^{-1}\right.$ and $6000 \mathrm{~g} \cdot \mathrm{mol}^{-1}$; Sigma, USA) were added.

\subsection{High-Performance Anion-Exchange Chromatography with Pulsed Amperometric Detection (HPAEC-PAD)}

Synthesized oligosaccharides were analyzed by high HPAEC-PAD using a Dionex CarboPac PA100 (Thermofisher, Barcelona, Spain) $4 \times 250 \mathrm{~mm}$ column at room temperature. A gradient of sodium acetate (from 6 to $300 \mathrm{mM}$ in $28 \mathrm{~min}$ ) was applied in $150 \mathrm{mM} \mathrm{NaOH}$ at a flow rate of $1 \mathrm{~mL} \cdot \mathrm{min}^{-1}$. Detection was performed with an ED40 Dionex module gold electrode and a reference electrode $\mathrm{pH} \mathrm{Ag} / \mathrm{AgCl}$. Standards used were glucose, fructose, sucrose, panose, and leucrose, prepared as $10 \mathrm{mg} \cdot \mathrm{mL}^{-1}$ in buffer $20 \mathrm{mM} \mathrm{NaAc}$ (pH 5.4). The samples were diluted 10 times in water and were filtered through membranes with pores of $0.20 \mu \mathrm{m}$ (Sartorius) before injection.

\subsection{High-Performance Size Exclusion Chromatography (HPSEC)}

Dextran molecular weights were determined by HPSEC. Two Shodex OH-Pack SB-805 and SB-802.5 columns were maintained in series, using an eluent containing $0.45 \mathrm{M}$ of $\mathrm{NaN}_{3}$ and $1 \%$ of ethylene glycol at a flow rate of $0.3 \mathrm{~mL} \mathrm{~min}^{-1}$. Columns and guard columns were maintained at $70^{\circ} \mathrm{C}$, and samples were filtered through a $0.45 \mu \mathrm{m}$-pore-size filter (Sartorius) before injection [29]. The reaction was stopped after $24 \mathrm{~h}$ by heating for 5 min at $95^{\circ} \mathrm{C}$ in a boiling water bath. Calibration standards of commercial dextrans of $2 \times 10^{6} \mathrm{~g} \cdot \mathrm{mol}^{-1}, 530,103 \mathrm{~g} \cdot \mathrm{mol}^{-1}, 70 \times 10^{3} \mathrm{~g} \cdot \mathrm{mol}^{-1}$, and $10 \times 10^{3} \mathrm{~g} \cdot \mathrm{mol}^{-1}$ (Sigma-Aldrich) were used.

\section{Conclusions}

Both enzymes were able to produce HMM and LMM polymers from sucrose, and isomaltooligosaccharides from sucrose/maltose. They were also able to modify at least two kinds of linear dextrans (1500 and $6000 \mathrm{~g} \cdot \mathrm{mol}^{-1}$ ), making the DSR-F- $\Delta$ SP- $\Delta$ GBD-CBM2a and DSR-F- $\Delta$ SP- $\Delta$ GBD biocatalysts act as efficient $\alpha$-transglucosidases in the presence of sucrose and linear oligodextrans. The additional cellulose-binding domain of the fusion 
enzyme does not affect the modification capacity on linear oligodextrans. Investigation of the relationship between structure and function of DSR-F variants will undoubtedly improve understanding of the polymerization mechanism of this enzyme and of GH70 glucansucrases in general. Considering its specificity, this fusion variant holds great potential for the production of novel functional foods.

Author Contributions: Conceptualization, R.F.V. and R.C.A.R.; methodology, L.T.M.V.; software, R.F.V. and E.D.; validation, M.L.G., A.M.A. and A.R.S.; formal analysis, R.F.V.; investigation, R.F.V., M.L.G., A.M.A. and A.R.S.; resources, E.D.; data curation, R.F.V.; writing—original draft preparation, R.F.V.; writing — review and editing, R.F.V.; supervision, E.D.; project administration, B.M.; funding acquisition, B.M. All authors have read and agreed to the published version of the manuscript.

Funding: This research and the ACP were funded by Development Research Project financed by the Development Cooperation Program of ARES (Académie de Recherche et d'Enseigment Supérieur) from Belgium (2017-2022).

Acknowledgments: Reinaldo Fraga Vidal and Roberto C. Aríticas Ribalta were supported by a Development Research Project financed by the Development Cooperation Program of ARES (Académie de Recherche et d'Enseigment Supérieur) from Belgium (2017-2022). Reinaldo Fraga Vidal thanks William David Rau (MS Rau Antiques, New Orleans, LA, USA) for his kind support. We thank Magali Remaud-Simeon and Pierre Monsan for their technical support. We also thank Joan Combie for the style correction of the manuscript.

Conflicts of Interest: The authors declare no conflict of interest. The funders had no role in the design of the study; in the collection, analyses, or interpretation of data; in the writing of the manuscript, or in the decision to publish the results.

\section{References}

1. Pu, Y.; Zou, Q.; Hou, D.; Zhang, Y.; Chen, S. Molecular weight kinetics and chain scission models for dextran polymers during ultrasonic degradation. Carbohydr. Polym. 2017, 156, 71-76. [CrossRef] [PubMed]

2. Zannini, E.; Waters, D.M.; Coffey, A.; Arendt, E.K. Production, properties, and industrial food application of lactic acid bacteriaderived exopolysaccharides. Appl. Microbiol. Biotechnol. 2016, 100, 1121-1135. [CrossRef]

3. Vettori, M.H.P.B.; Blanco, K.C.; Cortezi, M.; De Lima, C.J.B.; Contiero, J. Dextran: Effect of process parameters on production, purification and molecular weight and recent applications. Diálogos Cienc. 2012, 171-186. [CrossRef]

4. Ryan, P.M.; Ross, R.P.; Fitzgerald, G.F.; Caplice, N.M.; Stanton, C. Sugar-coated: Exopolysaccharide producing lactic acid bacteria for food and human health applications. Food Funct. 2015, 6, 679-693. [CrossRef] [PubMed]

5. Salazar, N.; Gueimonde, M.; De Los Reyes-Gavilán, C.G.; Ruas-Madiedo, P. Exopolysaccharides Produced by Lactic Acid Bacteria and Bifidobacteria as Fermentable Substrates by the Intestinal Microbiota. Crit. Rev. Food Sci. Nutr. 2016, 56, 1440-1453. [CrossRef] [PubMed]

6. Xu, L.; Zhang, J. Bacterial glucans: Production, properties, and applications. Appl. Microbiol. Biotechnol. 2016, 100, 9023-9036. [CrossRef] [PubMed]

7. Naessens, M.; Cerdobbek, A.; Soetaert, W.; Vandamme, E.J. Leuconostoc dextransucrase and dextran: Production, properties and applications. J. Chem. Technol. Biotechnol. 2005, 80, 845-860. [CrossRef]

8. Chen, Z.; Ni, D.; Zhang, W.; Stressler, T.; Mu, W. Lactic acid bacteria-derived $\alpha$-glucans: From enzymatic synthesis to miscellaneous applications. Biotechnol. Adv. 2021, 47, 107708. [CrossRef]

9. Badel, S.; Bernardi, T.; Michaud, P. New perspectives for Lactobacilli exopolysaccharides. Biotechnol. Adv. 2011, 29, 54-66. [CrossRef]

10. Zdolsek, H.J.; Vegfors, M.; Lindahl, T.L.; Tornquist, T.; Bortnik, P.; Hahn, R.G. Hydroxyethyl starches and dextran during hip replacement surgery: Effects on blood volume and coagulation. Acta Anaesthesiol. Scand. 2011, 55, 677-685. [CrossRef]

11. Monchois, V.; Remaud-Simeon, M.; Russel, R.R.; Monsan, P.; Willemot, R.M. Characterization of Leuconostoc mesenteroides NRRL B-512F dextransucrase (DSRS) and identification of amino-acid residues playing a key role in enzyme activity. Appl. Microbiol. Biotechnol. 1997, 48, 465-472. [CrossRef] [PubMed]

12. Lombard, V.; Golaconda Ramulu, H.; Drula, E.; Coutinho, P.M.; Henrissat, B. The Carbohydrate-active enzymes database (CAZy) in 2013. Nucleic Acids Res. 2014, 42, D490-D495. [CrossRef] [PubMed]

13. Passerini, D.; Vuillemin, M.; Ufarté, L.; Morel, S.; Loux, V.; Fontagné-Faucher, C.; Monsan, P.; Remaud-Siméon, M.; Moulis, C. Inventory of the GH70 enzymes encoded by Leuconostoc citreum NRRL B-1299-identification of three novel-transglucosylases. FEBS J. 2015, 282, 2115-2130. [CrossRef] [PubMed]

14. Gangoiti, J.; van Leeuwen, S.; Gerwig, G.; Duboux, S.; Vafiadi, C.; Pijning, T.; Dijkhuizen, L. 4,3- $\alpha$-Glucanotransferase, a novel reaction specificity in glycoside hydrolase family 70 and clan GH-H. Sci. Rep. 2017, 7, 39761. [CrossRef] 
15. Macgregor, E.A.; Jespersen, H.M.; Svensson, B. A circularly permuted alpha-amylase-type alpha/beta-barrel structure in glucan-synthesizing glucosyltransferases. FEBS Lett. 1996, 378, 263-266. [CrossRef]

16. Vujicić-Zagar, A.; Dijkstra, B.W. Monoclinic crystal form of Aspergillus niger alpha-amylase in complex with maltose at 1.8 angstroms resolution. Acta Crystallogr. Sect. F Struct. Biol. Cryst. Commun. 2006, 62, 716-721. [CrossRef]

17. Pijning, T.; Vujicic-Zagar, A.; Kralj, S.; Eeuwema, W.; Dijkhuizen, L.; Dijkstra, B.W. Biochemical and crystallographic characterization of a glucansucrase from Lactobacillus reuteri 180. Biocat. Biotrans. 2008, 26, 12-17. [CrossRef]

18. Molina, M.; Cioci, G.; Moulis, C.; Séverac, E.; Remaud-Simeon, M. Bacterial $\alpha$-Glucan and branching sucrases from GH70 Family: Discovery, structure-function relationship studies and engineering. Microorganisms 2021, 9, 1607. [CrossRef]

19. Fraga, R.; Moulis, C.; Escalier, P.; Remaud-Simeón, M.; Monsan, P. Isolation of a Gene from Leuconostoc citreum B/110-1-2 Encoding a Novel Dextransucrase Enzyme. Curr. Microbiol. 2011, 62, 1260-1266. [CrossRef]

20. Fraga, R.; Martínez, A.; Moulis, C.; Escalier, P.; Morel, S.; Remaud-Siméon, M.; Monsan, P. A novel dextransucrase is produced by Leuconostoc citreum strain B/110-1-2: An isolate used for the industrial production of dextran and dextran-derivatives. J. Ind. Microbiol. Biotechnol. 2011, 38, 1499-1503. [CrossRef]

21. Fraga, R.; Pacios, S.; Arísticas, R.C.; Martínez, L.; Lafargue, M.; Montes, A.; Remaud-Simeon, M.; Monsan, P. Cloning and Partial Characterization of an Extracellular Dextransucrase Coding Region (DSR-V) from Leuconostoc citreum M-3. In Microbial Exopolysaccharides: Current Research and Developments, 1st ed.; Duru, Ö.A., Ed.; Caister Academic Press: Norfolk, UK, 2019; Chapter 11; pp. 295-314. [CrossRef]

22. Joucla, G.; Pizzut, S.; Monsan, P.; Remaud-Simeon, M. Construction of a fully active truncated alternansucrase partially deleted of its carboxy-terminal domain. FEBS Lett. 2006, 580, 763-768. [CrossRef]

23. Olivares-Illana, V.; López-Munguía, A.; Olvera, C. Molecular characterization of inulosucrase from Leuconostoc citreum: A fructosyltransferase within a glucosyltransferase. J. Bacteriol. 2003, 185, 3606-3612. [CrossRef] [PubMed]

24. Vuillemin, M.; Claverie, M.; Brison, Y.; Séverac, E.; Bondy, P.; Morel, S.; Monsan, P.; Moulis, C.; Remaud-Siméon, M. Characterization of the first $\alpha-(1 \rightarrow 3)$ branching sucrases of the GH70 family. J. Biol. Chem. 2016, 291, 7687-7702. [CrossRef] [PubMed]

25. Parlak, M.; Ustek, D.; Tanriseven, A. Designing of a novel dextransucrase efficient in acceptor reactions. Carbohydr. Res. 2014, 386, 41-47. [CrossRef] [PubMed]

26. Hong, J.; Wang, Y.; Ye, X.; Percival Zhang, Y.H. Simple protein purification through affinity adsorption on regenerated amorphous cellulose followed by intein self-cleavage. J. Chromatogr. A 2008, 1194, 150-154. [CrossRef]

27. Meng, X.; Dobruchowska, J.M.; Pijning, T.; Gerwig, G.J.; Kamerling, J.P.; Dijkhuizen, L. Truncation of domain V of the multidomain glucansucrase GTF180 of Lactobacillus reuteri 180 heavily impairs its polysaccharide-synthesizing ability. Appl. Microbiol. Biotechnol. 2015, 99, 5885-5894. [CrossRef]

28. Molina, M.; Moulis, C.; Monties, N.; Pizzut-Serin, S.; Guieysse, D.; Morel, S.; Cioci, G.; Remaud-Simeon, M. Deciphering an undecided enzyme: Investigations of the structural determinants involved in the linkage specificity of alternansucrase. ACS Catal. 2019, 9, 2222-2237. [CrossRef]

29. Moulis, C.; Joucla, G.; Harrison, D.; Fabre, E.; Potocki-Veronese, G.; Monsan, P.; Remaud-Simeon, M. Understanding the polymerization mechanism of glycoside-hydrolase family 70 glucansucrases. J. Biol. Chem. 2006, 281, 31254-31267. [CrossRef]

30. Molina, M.; Moulis, C.; Monties, N.; David, G.; Morel, S.; Cioci, G.; Remaud-Simeon, M. A specific oligosaccharide-binding site in the alternansucrase catalytic domain mediates alternan elongation. J. Biol. Chem. 2020, 295, 9474-9489. [CrossRef] [PubMed]

31. Tsuchiya, H.M.; Hellman, N.N.; Koepsell, H.J. Factors affecting the molecular weight of enzymatically synthesized dextran. J. Am. Chem. Soc. 1953, 75, 757-758. [CrossRef]

32. Bechtner, J.; Hassler, V.; Wefers, D.; Vogel, R.F.; Jakob, F. Insights into extracellular dextran formation by Liquorilactobacillus nagelii TMW 1.1827 using secretomes obtained in the presence or absence of sucrose. Enzyme Microb. Technol. 2021, 143, 109724. [CrossRef] [PubMed]

33. Zhang, Y.-H.P.; Cui, J.; Lynd, L.R.; Kuang, L.R. A transition from cellulose swelling to cellulose dissolution by 0 -phosphoric acid: Evidence from enzymatic hydrolysis and supramolecular structure. Biomacromolecules 2006, 7, 644-648. [CrossRef]

34. Sumner, J.; Howell, S. A method for determination of invertase activity. J. Biol. Chem. 1935, 108, 51-54. [CrossRef]

35. Bradford, M.M. A rapid and sensitive method for the quantitation of microgram quantities of protein utilizing the principle of protein-dye binding. Anal. Biochem. 1976, 72, 248-254. [CrossRef]

36. Miller, A.W.; Robyt, J.F. Detection of dextransucrase and levansucrase on polyacrylamide gels by the periodic acid-Schiff stain: Staining artifacts and their prevention. Anal. Biochem. 1986, 156, 357-363. [CrossRef]

37. Fernandez-Patrón, C.; Hardy, E.; Seoane, J.; Castellanos, L. Double staining of Coomassie blue-stained polyacrylamide gels by imidazole-sodium dodecyl sulfate-zinc reverse staining: Sensitive detection of Coomassie blue-undetected proteins. Anal. Biochem. 1995, 224, 263-269. [CrossRef] 